Richard Cuthbertson is Senior Research Fellow at Saïd Business School, University of Oxford.

Steve Messenger is Director at Red Route International.

\title{
Collaborative CRM: A missed or a mythical opportunity
}

\author{
Richard Cuthbertson and Steve Messenger
}

Received: 5 February 2008

\begin{abstract}
This paper considers the way in which retailers and manufacturers work together to maximise sales. The paper highlights key issues surrounding the successful development of customer relationship management (CRM), and explores these issues with practitioners from a range of leading retail and manufacturing companies in order to identify possible solutions. The results of the analysis show that real collaborative CRM is only possible through aligning attitudes and measurements while acting independently to create combined consumer benefit.

Journal of Direct, Data and Digital Marketing Practice (2008) 9, 354-362. doi:10.1057/dddmp.2008.3
\end{abstract}

Keywords: CRM, collaborative CRM, category value, customer loyalty
Richard Cuthbertson Saïd Business School University of Oxford Oxford OX1 5NY, UK Tel: +44(0)1865 288876 Fax: $+44(0) 1865422501$ E-mail: richard.cuthbertson@sbs. ox.ac.uk

\section{Introduction}

For several years now, retailers such as Tesco and Sainsbury's have promoted 'collaborative CRM' as a potential win-win for both manufacturer and retailer in growing category value and customer (ie shopper) loyalty. It is clear from discussions with manufacturers and retailers alike that this potential is not being fully realised, despite the very obvious benefits it could bring. This paper explores the current situation and aims to provide some practical guidelines for future development.

\section{Collaborative CRM}

There are many definitions of customer relationship management (CRM). In broad terms, Galbreath ${ }^{1}$ proposes that CRM refers to the:

'activities an enterprise performs to identify, select, acquire, develop, and retain increasingly loyal and profitable customers.'

This is a very broad definition and reflects the fact that CRM activities may touch upon almost every aspect of a business. In Fast Moving Consumer Goods industries, 'collaborative CRM' is where retailers and manufacturers work together to achieve these aims. There is, however, a danger that CRM has become associated solely with the technology involved in managing the capture, storage and analysis of customer information to provide the necessary knowledge for the retailer's proposition to reflect individual customer requirements. This is especially true where CRM has resulted in costly failures. In the past, Crosby and Johnson ${ }^{2}$ claimed that:

'industry studies show that $60 \%$ of CRM software installations fail'. 


\section{The way in which CRM is implemented is crucial}

\section{Complex human interaction}

interaction

\section{Three stages}

There are many reasons given for such failures, often relating to CRM being driven by information technologists rather than marketers, as Mitchell ${ }^{3}$ states:

'The real problem with CRM is that it is not a marketing-driven concept.'

So, the way in which CRM is implemented is crucial, especially given that CRM can be very expensive. Indeed, there are many CRM practitioners and researchers outlining the key issues in CRM, such as Davids' 'How to avoid the 10 biggest mistakes in CRM' and Barlow's 'Loyalty marketing: what's it's role in a CRM world?'. Such articles are broad in scope and tend to offer similar generic advice: make sure you know why you are using CRM; manage the costs, especially those relating to information systems; measure the results and learn. More focused work tends to concentrate on the performance measurement and the data analysis aspects of CRM, such as Hirschowitz's ${ }^{6}$ 'transforming customer insight into customer value' and Starkey and Woodcock's 'REAP' measurements (retention, efficiency, acquisition and penetration).

While these papers provide some important guidelines and technical notes for successful CRM practice, they tend to imply that one organisation has control of the CRM interaction and that it is heavily systems-dependent. Customer loyalty, however, is most likely to be gained when the customer has both a rational argument in terms of store and product, such as this is the lowest price or highest quality product at the most convenient or closest store, combined with an emotional tie, such as feeling good about buying a particular product at a particular store. This is summarised by Brian Woolf, ${ }^{8}$ who stated:

'Man is an economic animal in search of self-importance.'

So, the ultimate source of successful collaborative CRM is not a technological interaction between one organisation's departmental IT systems with another, but rather the result of a complex human interaction based on the level of trust that exists between a retailer and a manufacturer, supported by IT systems and centred on creating a combined competitive advantage for the customer. This paper focuses on these critical elements of collaborative CRM.

\section{Methodology}

The approach to this research consists of three stages: a literature review to highlight conceptual approaches to collaborative CRM, informal discussions with practitioners to highlight potential practical problems with collaborative CRM and focus group-based workshops with retailers and manufacturers to explore the conceptual and practical issues highlighted with the aim of identifying any problems and proposing solutions.

The practitioners invited to attend the workshops consisted of managers involved in CRM-related activities from the following organisations: Allied Bakeries, BDC Electricals, Black \& Decker, 


\section{Workshops}

Britvic, Carphone Warehouse, Chefaro, Coca-Cola, Diageo, Homebase, L'Oreal, Mars Masterfoods, Motorola, Nestle, Sainsbury's, Tetley, Unilever and William Grants.

Prior to each workshop, a selection of pre-reading was sent out. This included a detailed paper proposing an integrated framework for collaborative CRM through the construct of the enterprise model $\left(\mathrm{Chan}^{9}\right)$, a conceptual forward-looking article on real-time CRM $\left(\right.$ Goldenberg ${ }^{10}$ ) and an example of collaborative CRM in practice (Cuthbertson and Messenger ${ }^{11}$ ).

The results of the informal discussions with practitioners were summarised in the form of questions and sent out prior to the workshop. Participants in the workshops were asked to be prepared to share their own views, experiences and recommendations during the workshop.

The key questions to be explored in the workshops were the following:

- Are there irreconcilable structural barriers, such as retailer margin differences between own label and branded products, which will always prevent successful collaboration?

- Is the source of funding within manufacturers for such collaborative marketing too ill defined to enable manufacturers to see it as a valuable media channel in the same way as conventional media?

- Is the price charged by retailers for using this channel too high and/or are the rules on its usage too restrictive? In other words, are retailers talking a 'media channel story' but not 'walking it'?

- Is there a conflict between the retailer's customer segments, the manufacturer's consumer segments and the realities of shopper marketing practice that make it impossible for the retailer and manufacturer to agree on which products to stock and promote to which individual customers? If so, is there a solution?

- Are retailers placing so many restrictions on the way they allow manufacturers to use the channel that it is impossible for a collaborative approach to ever be achieved? In other words, do they really believe in such collaboration or is it too much of a risk?

- Is a simple data sharing issue at the heart of the problem? How could manufacturers and retailers cooperate better in this respect?

- Is 'scalability' of the CRM activity through a retailer programme a real issue or should manufacturers be thinking and using these channels in a completely new and different way?

Participants were also asked to consider potential solutions, guided by the following questions:

- What common strategic goals must retailers and manufacturers have to successfully undertake collaborative relationship marketing?

- What complementary skills do retailers and manufacturers have that can help deliver enhanced relationship marketing? 
- Are there any tangible models of how collaborative relationship marketing could work and what would be the pros and cons of them?

During the workshops, the pre-reading was discussed, followed by consideration of the questions above. Within the second workshop, participants were split between retailers and manufacturers into two focus groups to discuss these issues before coming together for a plenary session to agree on outcomes. This achieved a more effective result than the first workshop where the group was not split according to different perspectives, the subsequent discussion was less partisan and sensitive issues were not so clearly expounded as a result.

\section{Outcomes}

\section{Key perspectives identified}

\section{Analysis of points raised}

To structure the results of the workshop discussions and to reflect the strategic impact of employing collaborative CRM, an adaptation of Kaplan and Norton's ${ }^{12}$ architecture for a balanced scorecard approach to management strategy was employed, which identifies the following key perspectives: financial, customer, internal and learning and growth. In this adaptation, the:

- Financial perspective focuses on the funding and pricing components of the retailer-manufacturer relationship.

- Customer perspective focuses on the various segmentation issues of key customers for the retailer and/or manufacturer.

- Internal perspective focuses on the management, systems and organisational requirements of the retailer and/or manufacturer.

- Learning and growth perspective focuses on future development, and in particular on the learning that is shared between retailer and manufacturer.

Using this structure, the following points that were raised in the group discussions can be analysed.

From the financial perspective, retailers and manufacturers can always collaborate as long as there is some clear financial gain for both parties. All parties are motivated by improving market share, revenue and profit - this is the common ground. The difficulty lies in measuring that financial gain, usually as a return-on-investment (ROI), and splitting the benefit accordingly. Although it is generally accepted that manufacturers may fund much of the initial investment, the division of benefits is vigorously debated with manufacturers perceiving that they are not 'getting their fair share'.

The customer perspective provided less of an issue. It is generally agreed that although key segments may differ between retailers and manufacturers, subsequent data analysis should be able to provide both shopper and consumer perspectives.

The internal perspective provided the most significant obstacle to developing collaborative CRM. There was a general lack of strategic alignment between retailers and manufacturers, regardless of individual strategies. This lack of natural mutuality militates against fully 


\section{Learning and growth perspective is critical}

\section{Competing financial objectives can be resolved}

collaborative CRM. For example, retailer policy may preclude adopting a recommendation that might potentially grow category sales but would undermine private label product. Interestingly, while it is accepted that IT systems are not necessarily well integrated, this is not seen as an effective barrier against data sharing. The more critical issue around data concerns the commercial implications, in that data are often not shared freely and are more usually sold (perhaps indirectly) by the retailer to the manufacturer. Moreover, the long-term learnings from retailer data analysis across a range of manufacturers are often not shared, and so undermine fully collaborative CRM.

Indeed, the learning and growth perspective proves to be critical in understanding the retailer-manufacturer quandary. Both retailer and manufacturers have concerns about the subsequent sharing of learnings from any successful collaborative CRM initiative. In particular, manufacturers are concerned that retailers will take any learning and share it with other manufacturers, or even worse, use it to develop private label product. On the other hand, retailers are concerned about manufacturers sharing learnings with other retailers. These attitudes help create a competitive environment but also ensure that any competitive advantage gained from successful collaborative CRM is quickly reduced, and thus discourages longer-term investment.

Hence, retailers and manufacturers may have competing financial objectives but these can be resolved given sufficient information and negotiation. Differences in targeted customer segments may be similarly resolved and there is certainly agreement on the overall customer focus of collaborative CRM. However, the full potential of collaborative CRM is undermined by the need to remain competitive. Internal objectives will take precedent over collaborative objectives, and any learnings from success (and failure) will be quickly transferred (or avoided) to create further growth. Thus, retailers will encourage manufacturers to compete against one another, as well as to protect their own private label interests where necessary, while manufacturers will take learnings from one successful retailer interaction into other retailers.

In summary, it is clear that each party will only join in collaborative CRM if there is a clear potential benefit to both parties (retailer and manufacturer). Therefore, the basic issue relates to trust and how best to create a combined competitor advantage within the realms of collaborative research and information sharing.

\section{Implications}

Given the inherent competitive background to retailer-manufacturer relationships, the shared goal of developing customer demand for mutual benefit might appear to be unattainable. Many of the difficulties encountered, however, stem from the attitudes of the parties involved.

To date, most collaborative CRM initiatives have typically focused on driving operational efficiencies (as opposed to effectiveness) in ranging and merchandising (where the retailer usually gains but the manufacturer only sometimes), pricing (where only the retailer seems to gain) and 'one-to-one vouchering' (where the manufacturer often 
Increasing levels of manufacturer insight

\section{'Universal' shopper types}

gains but also pays for the investment). These have led to the current levels of dissatisfaction with collaborative CRM among many manufacturers.

More recent examples of retailer-manufacturer CRM collaboration look more promising. They are based on a more even balance of information sharing, an open recognition of the roles that each partner plays, and the support of an unbiased third party in providing objective and impartial analyses, research and interpretation. To demonstrate this we can cite, in anonymous form, several current examples.

Each of these examples is an illustration of the increasing levels of manufacturer insight into the area of understanding shopper behaviour and motivations, and how these in turn link both to choice of store and to the role they play in fulfilling consumer needs. By investing in independent shopper marketing research that can be laid alongside the retailer's customer level transactional data, manufacturers are obtaining deeper insights into each shopper's motivations for buying from the category, how that category (and brand and product) drives their choice of where to buy their whole basket of goods (beyond simple locational convenience) and how to make the category more appealing, retailer by retailer, outlet by outlet.

The outcomes from this research bring a deep understanding of 'universal' shopper types and shopping occasions (or 'missions'). For example, it is not uncommon to derive macro shopper types, such as convenience driven, price driven, quality driven, clever and occasional shoppers, and find that these exist across countries as well as across retailers. Similarly, missions, such as Weekly Stock-up, Top-Up Shop, On-the-Go and so forth, can be found in every market and it is the combination of these, together with the requirement to meet consumer needs and the choice of available shopping options that dictate actual shopper behaviour. These 'universal' shopper types and shopping missions are inherently more useful to the manufacturer for building a multi-retailer strategy and even more valuable when used in collaborative CRM initiatives. Such research provides insights that enable manufacturers to change the underlying growth rate in the category by re-designing it to better meet shopper needs. This is a step beyond improved efficiency and into improved effectiveness. By understanding how the needs of the consumer translate into the needs of the shopper, the stimulus that consumer need has on each shopping mission and how well each retailer is perceived at being able to deliver against each of these, the manufacturer can then focus the design and placement of new products, new packages, new displays and so on in a structured way to grow the business of each of its retail customers.

The manufacturer gains strongly from this, as they know how the mix of range, price, quality, convenience and service needs to be changed by the retailer to maximise the attractiveness of the category to differing shopper types. It also gives them more control over the value and profitability of the category because by attracting different mixes of shopper types and changing the products to better meet their needs, price becomes less of a driver. The balance of price versus 


\section{Three successful examples}

\section{'Super-retailer'}

benefit is changed. The retailer also gains strongly as more customers are attracted overall, average basket-spend increases, and category margins are improved. It is potentially a powerful formula.

\section{Examples in practice}

Based on the understanding above, the authors have observed three examples in which a more collaborative approach to CRM has successfully taken place. The full details of these mini case studies are currently commercially sensitive, though the authors have been able to independently verify their validity, including the financial effects.

The first example of this approach is for the coffee category in Australia during 2005-2006. In this instance, a leading manufacturer redesigned the whole manner in which coffee was presented to consumers. From above-the-line media, all the way through to in-store execution and collaborative CRM, different coffees are now presented in terms of how they will meet different consumption occasions ('consumer need states'), expanding the already recognised distinctions between caffeinated and decaffeinated, or between roast and ground, into providing a choice of coffees that the consumer can have in the home to meet the differing needs of refreshment, relaxation, socialising, stimulation, winding-down and so forth. The sales impact has been substantial and the initiative is now being rolled out across the globe.

The second example comes from soft drinks where a major global manufacturer has identified, retailer by retailer across retail sectors, the share of wallet spent on soft drinks by each shopper type on each type of shopping occasion. They have also established their own portfolio and brand shares on the same basis and, from this, have derived winwin opportunities for growing the category for key retail customers and for themselves. Using the additional understanding of the drivers of these shopper decisions, they have then been able to derive and jointly design and implement, with the retailers, shopper marketing plans that include the most appropriate and effective collaborative CRM programmes.

The third example is an alcoholic drinks manufacturer that has used the technique in the UK to better understand the drivers of promotional uplifts among differing shopper types as measured through loyalty card data. Once the 'shopper type by shopping mission by channel/retailer' framework is in place, the promotional uplifts are re-mined to uncover who was buying, when, and why, and implications for how to better promote the category are derived. This has led to the identification of a $£ 12 \mathrm{~m}$ opportunity on $£ 200 \mathrm{~m}$ of brand sales and an even bigger potential gain for the retailers concerned.

These examples highlight the fact that a lone retailer may have very detailed information about 'what' shoppers are doing but only within their own establishments. The manufacturer has a broader but shallower view. By translating this wider 'view of the consumer' into 'a view of the shopper', a manufacturer can provide insight as if a 'super-retailer' for a single category or group of categories. This enables them to speak the retailer's language, manage shoppers at a country level, and derive 
how to use and leverage each retail store chain for mutual benefit by understanding the 'why' behind the 'what'.

\section{Conclusions}

The examples discussed have four key characteristics in common that reduce or incorporate the competitive element within the retailermanufacturer relationship.

The key characteristics for success appear to be the following:

\section{Key characteristics for success}

- The financial opportunity (and subsequent achieved gain) is independently measured in order to help both the retailer and manufacturer decide whether an approach is worth continuing, extending, adapting or renegotiating.

- The shopper impact is derived from a combined measurement incorporating retailer breadth with manufacturer depth for key segments and missions in order to decide whether an approach is worth continuing, extending, adapting or renegotiating.

- The management, systems and organisational requirements of the retailer and manufacturer are kept separate, but the information is brought together, where necessary, by the independent third party. This reflects the reality of the competitive environment which may require a third party to be used as a conduit.

- Both retailers and manufacturers are able to jointly learn and grow within the environment described. It must be accepted that they will want to leverage any learning across all of their activities and not restrict it (which may be considered to be against fair competition by the relevant authorities in any case). While these characteristics may not appear to provide a long-term, strategic, mutually beneficial, winwin approach, the greatest beneficiaries will be those retailers and manufacturers that are quickest to learn and respond to new growth opportunities. These will not be those retailers and manufacturers that are thinking only at a tactical level for short-term gain, but rather those that are working continuously over time in a stable relationship based on respect rather than trust, which may be supported by a mutually trusted third party.

In conclusion, the real potential yield of collaborative CRM will be harvested by those retailers and manufacturers that are aligned attitudinally while acting independently to create a combined consumer benefit. Further research is required to understand whether such a dichotomous relationship can be developed and grown over time, or whether it is purely dependent on the existing market situation and brands involved.

\section{References}

1. Galbreath, J. (1998) 'Relationship management environments', CreditWorld, NovemberDecember 1998, pp. 14-21. 


\section{然- Cuthbertson and Messenger}

2. Crosby, L. A. and Johnson, S. L. (2000) 'What to do before going 1-to-1', Marketing Management, Vol. 9, No. 4, pp. 15-21.

3. Mitchell, A. (2003) 'CRM failing as it yields one-sided relationships', Precision Marketing, 31/10/03, p. 14.

4. Davids, M. (1999) 'How to avoid the 10 biggest mistakes in CRM', Journal of Business Strategy, Vol. 20, No. 6, pp. 22-26.

5. Barlow, R. G. (2001) 'Loyalty marketing: What is it's role in a CRM world?', European Retail Digest, Vol. 31, pp. 9-11.

6. Hirschowitz, A. (2001) 'Closing the CRM loop: The 21st century marketer's challenge: Transforming customer insight into customer value', Journal of Targeting, Measurement and Analysis for Marketing, Vol. 10, No. 2, pp. 168-178.

7. Starkey, M. and Woodcock, N. (2002) 'CRM systems: Necessary, but not sufficient. REAP the benefits of customer management', Journal of Database Marketing, Vol. 9, No. 3, pp. 267-275.

8. Woolf, B. P. (1996). Customer Specific Marketing, Teal Books, USA.

9. Chan, J. O. (2005) 'Toward a unified view of customer relationship management', The Journal of American Academy of Business, March, pp. 32-38.

10. Goldenberg, B. (2006) 'The future of CRM: Real time', Customer Relationship Management, Vol. 10, No. 2, p. 16.

11. Cuthbertson, R. W. and Messenger, S. (2006) 'Marrying market research and customer relationship marketing: Are they good bedfellows?', Journal of Direct, Data and Digital Marketing Practice, Vol. 8, No. 2, pp. 109-120.

12. Kaplan, R. S. and Norton, D. P. (2001). The Strategy-Focused Organization, Harvard Business School Publishing Corporation, Boston, MA, pp. 76-77. 